\title{
The Adaptive Erasmus Mundus Cartography M.Sc. Program in the Covid-19 Pandemic from a Student's Perspective
}

\author{
Xiyu Wang ${ }^{\mathrm{a}, *}$, Jonathan C. King ${ }^{\mathrm{b}}$ \\ a Technical University of Munich, xiyu2048@163.com \\ ${ }^{b}$ Technical University of Munich, jonathanclarkking87@gmail.com \\ * Corresponding author
}

Keywords: Cartography, Covid-19 pandemic, online learning, adaptive, re-organization, uncertainty, mutual support

\begin{abstract}
:
The Erasmus Mundus Cartography M.Sc. Program (hereafter referred to as "the Program") is a prestigious international master's degree program of four universities: TU Munich, TU Wien, TU Dresden and Uni Twente. It is so far the only Erasmus Mundus Joint Master Program with a primary focus on the study of cartography. Since last year, the Program has been significantly influenced by the Covid-19 pandemic, particularly regarding an unprecedented shift to online (and eventually hybrid) educational format. However, students and teachers involved in the Program adapted to these shifts throughout time. This abstract recounts the experiences of being a student in the Program during the pandemic and presents valuable insights gained from these experiences.
\end{abstract}

\section{The Major Re-Organizations that Happened in Education}

The pandemic caused some major changes to the Program's educational methods and contents. Firstly, the topic "Definitions of Cartography and Map" was added for the first time to the topic list of Seminar of Geosciences, a course about advanced scientific research on a topic of their choice related to current cartographic problems. Unlike many other topics that focused on modern cartographic developments, "Definitions of Cartography and Map" required a hermeneutic research methodology. Moreover, the history of cartography and map is nearly as long as human history, but the precise definition of these two concepts is always evolving and worthy of discussion and debate (it is in the ICA research agenda (icaci.org, 2021)). The long-standing history of these two concepts also resulted in a larger-than-usual research endeavor for the student who chose this topic. Thanks to the increased free time available each day due to the pandemic, she was able to dive deeper into valuable literature than would have been the case otherwise and establish an elaborated work process. For example, a great part of the time she would have spent commuting between home and university was instead devoted to thinking thoroughly about the definitions of the two words "cartography" and "map".

Secondly, assignments with a thematic focus on the pandemic offered a precious opportunity for students to learn about a problem affecting the entire world. Last March, while studying at TU Wien, one student created a storytelling map in the course Project Map Creation entitled "Europe Walking through the Darkest Hour" to illustrate the influences of and precautions associated with Covid-19 in Europe. Project Map Creation teaches static map design on a self-chosen topic, and the student was the only one who chose to depict this currently most relevant event. In mid-April, in the course Multimedia Cartography \& Geocommunication, students were asked to complete assignments with a theme focus of "epidemic/pandemic". This course introduced story map, dashboard and dynamic website to illustrate an ever-changing geospatial event. In the fall and winter of 2020 and 2021, students completing the semester of the program at TU Munich were required to do group work about the pandemic for a course called Mapping Project. At the end of the semester, students presented their work at a virtual vernissage entitled "Pandemic on Maps." In 2021, there is even a thesis topic dedicated to visualizing the spread of covid-19. All of these educational experiences draw students' attentions to the most severe current worldwide public health issue, and they help students learn to act as responsible global citizens.

Other good things brought about by pandemic-related shifts regard academic communication taking place "beyond the walls of a lecture hall" (European Union, 2020). Thanks to online conferencing platforms, all planned guest lectures took place on time. Additionally, students were able to attend thesis defenses of students one year senior to them, have afterhour Q\&A sessions with students from other Program intakes and appreciate the Mapping Project vernissage of students one year junior to them. In the final semester, students were also welcomed to attend their peers' Extended Research Proposal (ERP) defenses. These virtual events effectively compensated for a lack of on-campus academic activities, and they fostered connections among students enrolled in different years. Besides, online learning allowed everyone to "access, create and share digital materials without constraints of location and timetable" (European Union, 2020). For instance, the recorded lectures not only benefited students with multiple daily tasks other than studying. They also helped teachers during the end-of-semester reflection.

Online learning undoubtfully reshaped the program, but it is not omnipotent: It cannot replace courses whose main education is in the field, featuring activities such as field mapping, cartographic surveying and high-mountain cartography. An example of such a course is Alpine Cartography Field School (ACFS). Last autumn, ACFS, an important program tradition involving an excursion in the rugged mountain range at Ramsau am Dachstein, fortunately took place despite the pandemic, courtesy of a convincing hygiene concept put forward by three teachers from TU Dresden and the low 
Covid-19 infection in both Germany and Austria at that time. During the day excursions and evening debriefings, nonpharmaceutical precautions were compulsory to prevent Covid-19 from spreading when enough personal space could not be guaranteed. Participating students perhaps benefitted from completing ACFS during the pandemic in ways they may not have if they did this at a time when there wasn't a pandemic: Their "soft power" concerning their own and others health was improved when planning for the safest travel to Ramsau am Dachstein, as well as sharing accommodation in small groups. Teamwork skills were also strengthened throughout ACFS, especially in during preparation for and delivery of group presentations about intriguing topics such as tangible relief models, laser scanning, panoramic maps, glaciology, and mobile weather mapping among others. The ACFS was a successful start for all other courses at TU Dresden with on-site education, where strong precautions were necessary due to the pandemic.

Another great on-site experience was the indoor navigation experiment conducted by the lecturer of Multimedia Cartography \& Geocommunication in the main building of TU Wien last summer. It also took place thanks to rigorous hygiene concepts: Multiple time slots per day were offered, but only one student, with a medical mask and gloves on, was allowed to participate in the experiment at a time. Students beforehand were required to fill out a letter of commitment to obey any precautions. The experiment involved using a path shown on a smart phone to navigate to a target. After completing this task, students were asked to indicate the relative orientation of the ending and starting points of the navigating task, illustrate the routes they used to navigate on a floor plan, identify photos of landmarks (important crosses, turns and staircases) along the routes and so on. All experiment tasks prudently tested students' sense of direction in diverse aspects, especially those regarding multi-level navigation and landmark-based navigation. This experiment was the only on-campus academic experience for program students studying at TU Wien in the spring of 2020 (all other academic experiences during the four-month semester were online.) Students who participated in the experiment were able to have face-to-face conversations with their teachers, and they cherished this experience a great deal.

The global pandemic also builds up skills for students of cartography in solving uncertain, complex problems. Devising solutions to such problems, with their significant and ever-increasing number of semantic and non-structural attributes, requires an ever-adaptive synthesis of multiple forms of knowledge. Cartography's interdisciplinary synergy of constantly evolving fields in art, science, and technology represents such a synthesis. The interdisciplinarity of cartography is possibly demonstrated by thesis topic choices of students in the program this year. 12 out of 23 topics approved by Uni Twente concern cartographic research in subject areas that integrate knowledge from multiple domains, some of which including human emotion, enterprise development, education, migration crisis, etc. Students writing theses in subject areas gain a brand-new understanding of the two words "cartography" and "map."

\section{Mutual Support between the Students and Teachers}

The impact of the pandemic tightened the bond between students and teachers. First of all, apart from their enormous efforts regarding course re-organizations, teachers were flexible with assignments' deadlines, exam formats and grading systems. Second of all, teachers at TU Wien (and in TU Dresden in the following semester) held online carto talks to share the latest cartographic news. Alongside academic supports, they were aware that "sitting behind a screen all day may negatively affect concentration and can also be a burden on mental well-being." (European Union, 2020) Therefore, the Head Professor at TU Wien expressed his pity of everyone unable to "discuss and talk to each other side by side, gather and just be social human beings," and consoled students by addressing the importance of living well in uncertainty. When the "first wave" of the pandemic finally ended, the Head Professor organized two physical events: a three-hour hike at the highest natural point of Vienna and an end-of-semester meeting on campus. In both events, necessary precautions were repeatedly emphasized, because the uncertainty still existed and the crisis had not yet ended.

Students themselves also worked hard to maintain high levels of group cohesion and positivity. For example, to let teachers fully concentrate on increasing their digital competence, some students attempted to act as "casual online tutors" to answer other students' questions or help them with assignments when necessary. Even in the final semester when students were writing theses in various places, weekly Zoom coffee chats allowed them to regularly discuss thesisrelevant matters. Students also reached out to those who were enrolled in other programs at the universities where the Program take place through academic cooperation and daily conversations. Besides, in an Erasmus Mundus Joint Master's Degree Program, mobility takes up a decent percentage of students' free time. The pandemic caused immense difficulties in accommodation confirmation and travelling. Some students in the Program therefore tried to support other students by giving them KN95 masks sometimes during the travel and offering to transport luggage for them.

To summarize, the Covid-19 pandemic led to the closure of teaching buildings, campuses and other sites and a forced shift to online (or hybrid) learning. However, as is typical for other disaster and crises, it offered people a great learning experience. It accelerated changes in course re-organization in the Program worth keeping for the future, and helped students learn how to do wonderful things during a time of uncertainty. Everything mentioned above strongly verifies an old saying: Challenges and opportunities coexist.

\section{References:}

European Union. (2020). Digital Education Action Plan (2021-2027). https://ec.europa.eu/education/education-in-theeu/digital-education-action-plan_en Icaci.org. (2021). Cartographic Theory. https://icaci.org/research-agenda/cartographic-theory/ 